\title{
Presence of an older weaned companion influences feeding behavior and improves performance of dairy calves before and after weaning from milk
}

\author{
A. De Paula Vieira, M. A. G. von Keyserlingk, and D. M. Weary ${ }^{1}$ \\ Animal Welfare Program, University of British Columbia, 2357 Main Mall, Vancouver, BC, V6T 1Z4, Canada
}

\begin{abstract}
In commercial dairy production, calves are typically separated from the dam at a young age. This practice may interfere with developmental processes mediated by social interactions that occur between the calf, her dam, and older social partners. The aim of this study was to test the prediction that calves housed with an older weaned companion would show earlier intake of solid feed before weaning and higher growth rates during and after weaning compared with calves housed with calves of their own age. Forty-five dairy calves were separated from their dams and housed individually for approximately $7 \mathrm{~d}$. Afterward, calves were assigned to pens composed of groups of either 3 young calves or 2 young calves and an older weaned calf. Group pens were equipped with automatic milk, water, starter, hay feeders, and scales. Weaning was by gradual reduction of milk volume over $5 \mathrm{~d}$, from d 36 to d 40 . During the preweaning period (d 1 to $\mathrm{d} 35)$, the number (8.8 vs. $5.1 \pm 0.5$ visits/d per calf) and duration (13.2 vs. 8.2 $\pm 1.1 \mathrm{~min} / \mathrm{d}$ per calf) of visits to the hay feeder was higher for calves housed with an older companion, and calves in this treatment consumed more hay (57.9 vs. $25.6 \pm 4.7 \mathrm{~g} / \mathrm{d}$ ) than did calves housed in groups of similar age. Starter intake did not differ between treatments before weaning, but the number of visits (15.2 vs. $9.4 \pm 0.6$ visits/d) and the time spent at the starter feeder (6.5 vs. $3.4 \pm 0.5 \mathrm{~min} / \mathrm{d}$ ) were higher for calves housed with an older weaned companion. During the weaning period (d 36 to d 40), calves housed with an older companion spent more time at the starter feeder ( 22.1 vs. $12.9 \pm 1.9 \mathrm{~min} / \mathrm{d})$ and made fewer unrewarded visits to the milk feeder (17.0 vs. $26.1 \pm 1.9$ visits/d) than did calves housed in groups of similar age. During the postweaning period ( $\mathrm{d} 41$ to $\mathrm{d} 55$ ), calves housed with an older weaned companion spent less time at the hay feeder ( 32.5 vs. $58.5 \pm 5.5 \mathrm{~min} / \mathrm{d}$ ) and more time at the starter feeder ( 41.4 vs. $28.2 \pm 3.7 \mathrm{~min} / \mathrm{d}$ ), and consumed more starter (1.8 vs. $1.3 \pm 0.1 \mathrm{~kg} / \mathrm{d}$ ).
\end{abstract}

Received August 10, 2011.

Accepted February 1, 2012.

${ }^{1}$ Corresponding author: dan.weary@ubc.ca
Calves housed with an older weaned companion gained more weight during the preweaning (0.89 vs. $0.76 \pm$ $0.03 \mathrm{~kg} / \mathrm{d}$ ) and postweaning (1.4 vs. $1.1 \pm 0.05 \mathrm{~kg} / \mathrm{d}$ ) periods. We conclude that housing young calves with an older weaned companion stimulates feeding behavior and growth before and after weaning from milk.

Key words: dairy calf, group housing, social learning, solid feed

\section{INTRODUCTION}

On commercial dairy farms, calves are typically separated from the cow soon after birth and housed in single pens or in groups of similar age. The lack of access to a more experienced social partner may influence the early development of feeding behavior, especially the early intake of solid feed. Young animals seem more dependent on social learning to locate and select edible feedstuffs than are adults (Galef, 1977).

The calf's ability to find the teat and suckle successfully is influenced by the cow's behavior (Hafez and Lineweaver, 1968); as the calf ages, the cow behaves in ways that discourages milk intake (e.g., the cow gradually increases the time and distance away from her calf, allows fewer suckling bouts, and decreases nursing time; Reinhardt and Reinhardt, 1981; Vitale et al., 1986). This stimulates the calf to sample alternative feeds. For example, within the first few weeks of life, calves start sampling solid feed in the company of grazing adults (Key and MacIver, 1980; Nolte et al., 1990). Foraging with experienced social partners is known to decrease food neophobia and facilitate acceptance of novel foods (Lynch et al., 1983; Galef and Stein, 1985), and young grazers copy the dietary choices of adult members of the group, helping them avoid poisonous substances (Mirza and Provenza, 1994). Providing calves a novel diet in the presence of their dam biases calves' preference toward that diet for at least 12 wk after first exposure (Fukusawa et al., 1999).

Social learning of feeding may be particularly beneficial before and after weaning, the period when calves make the transition from a milk-based diet to solid feed. Calves that consume little solid feed before weaning are more likely to experience poor growth and prolonged 
hunger until intake of solid feed meets their requirements for maintenance and growth (De Paula Vieira et al., 2008; de Passillé et al., 2011).

The aim of this study was to test the prediction that young calves housed with an older weaned companion would ingest more solid feed before weaning, improving weight gains during and after the weaning period.

\section{MATERIALS AND METHODS}

This study used 54 Holstein dairy heifers housed at the University of British Columbia's (UBC) Dairy Education and Research Centre, Agassiz, Canada. The animal care protocol was approved by the UBC Animal Care Committee.

\section{Preexperimental Period}

All calves used in this study (including the older companions) were female and subjected to the same management practices during the early age. All calves were separated from their dams and fed colostrum within 8 $\mathrm{h}$ of birth. To assess the efficiency of passive immune transfer, blood samples were collected from the jugular vein of each calf within $24 \mathrm{~h}$ after the first feeding of colostrum, and serum was analyzed using a Reichert AR 200 digital hand-held refractometer (Reichert, Depew, $\mathrm{NY}$ ). Only calves having a serum protein level $>5.5 \mathrm{~g} /$ $\mathrm{dL}$ were included in the study. After colostrum feeding, the umbilical cord of all calves was treated with a $7 \%$ iodine solution. All calves were sedated and dehorned at $4 \mathrm{~d}$ of age using caustic paste (see Vickers et al., 2005). During this period, all calves were housed individually in sawdust-bedded pens measuring $1.2 \mathrm{~m} \times 2.0$ $\mathrm{m}$ and provided $8 \mathrm{~L}$ of whole milk divided in 2 meals/d. Calves had free access to water, hay, and starter during this period. Prior to group housing, all calves were subjected to a general clinical health examination by a veterinarian and only clinically healthy calves were included in this study. The older weaned companion calves were previously housed in groups of 3 animals and were habituated to feed from the automatic feeders before being housed with the younger calves.

\section{Experimental Period}

When younger calves were $8 \pm 2.5 \mathrm{~d}$ of age, they were assigned to pens composed of either groups of 3 young calves ( $\mathrm{n}=9$ groups), or groups of 2 young calves and an older weaned calf ( $\mathrm{n}=9$ groups). Groups were balanced by weight (mean $\pm \mathrm{SD}$; group of 3 young calves $46.6 \pm 5.4 \mathrm{~kg}$ vs. group of 2 young calves $46.9 \pm 5.6$ $\mathrm{kg}$ housed with an older weaned calf $121.5 \pm 8.4 \mathrm{~kg}$ ). Older weaned companions were $85 \pm 5.5 \mathrm{~d}$ old when group housed with the younger calves. The group pens measured $7.0 \mathrm{~m} \times 5.0 \mathrm{~m}$ and were equipped with automatic feeders.

The young calves were allowed access to $8 \mathrm{~L} / \mathrm{d}$ of pasteurized whole milk (a mixture of saleable and nonsaleable milk) provided by a CF1000CS-Combi automatic feeder (DeLaval, Tumba, Sweden); this feeder also provided free access to a textured calf starter (93\% DM) that contained $57.5 \%$ concentrate pellets, $14 \%$ flatted barley, $13 \%$ flatted oats, $10 \%$ steamroll corn, and $3.5 \%$ molasses (Unifeed Ltd., Chilliwack, BC, Canada).

Calves were trained by a caretaker to use the milk feeder. This training was carried out in the morning and afternoon of each of the first $3 \mathrm{~d}$ of the experimental period. A barrier at the entrance to the milk feeder prevented the older weaned companions from gaining access to this feeder but allowed access by the smaller calves. Weaning was carried out gradually starting on $\mathrm{d}$ 36 , with a reduction of milk volume by $1.6 \mathrm{~L} / \mathrm{d}$. From d 41 onward, milk was no longer provided. Chopped orchardgrass hay $(95 \% \mathrm{DM})$ with a mean particle size of $1.2 \pm 0.4 \mathrm{~cm}$ (calculated using the Penn State Particle Separator) and water (water intakes and visits were not measured) were also provided automatically (Insentec, Marknesse, the Netherlands). Visits to the feeders were defined as starting from the time the calf's transponder was detected by the feeder. Calves were weighed automatically at every visit to the milk feeder and water drinker by scales located underneath them (Smart 1, Westernscale Inc., Port Coquitlam, BC, Canada).

During the entire experimental period, older weaned companions performed (mean $\pm \mathrm{SD}$ ) $24.4 \pm 8.1$ visits $/ \mathrm{d}$ to the starter feeder. These visits lasted $54 \pm 18.6$ $\mathrm{min} / \mathrm{d}$ and calves consumed $3.6 \pm 1.4 \mathrm{~kg} / \mathrm{d}$ of starter. Visits to the hay feeder lasted $24 \pm 12 \mathrm{~min} / \mathrm{d}$ and older weaned calves performed $25.7 \pm 17.8$ visits/d. Older companions consumed $0.5 \pm 0.3 \mathrm{~kg} / \mathrm{d}$ of hay throughout the experiment.

Health checks were performed every $2 \mathrm{~d}$ consisting of (1) diarrhea scoring of calves $(1=$ normal feces; $2=$ plaques but not watery; 3 = watery) and cleanliness of the rump $(1=$ clean, $2=$ some fecal soiling; $3=$ heavily soiled with fecal matter); (2) clinical examination of the respiratory system (presence or absence of nasal discharge and pulmonary sounds using an stethoscope); (3) body temperature; and (4) inspection of the umbilical cord. Calves diagnosed as ill were rechecked daily and treated according to standard operating procedures developed by the herd veterinarian (e.g., administration of antibiotics, antiinflammatory drugs, electrolytic solutions, and topical iodine solution as required). Of the 27 calves housed with same-age companions, 11 were diagnosed with an inflammation in the umbilical cord and 12 were diagnosed as having diarrhea scores 
of 3 (some calves had a combination of the 2 conditions). Of the 18 calves housed with an older social companion, 4 were diagnosed with an inflammation in the umbilical cord and 6 were diagnosed as having diarrhea scores of 3. Again, some calves had a combination of the 2 ailments. No calves showed clinical signs of respiratory diseases. We found no treatment difference (as tested using Fisher's exact test) for any of these health measures, but readers should be cautioned that the study was not designed to assess health outcomes and a larger sample of calves would be required for meaningful analysis.

\section{Statistical Analyses}

Average daily gains were calculated for each of the younger calves from the slope of the regression between BW and age. These values were then averaged to calculate a mean value for each of the 18 test groups. The effect of treatment (1 df) on gains, average intake, time and number of visits to the drinker, and the milk, starter, and hay feeders were tested with group as the experimental unit (i.e., 16 error df) using the MIXED procedure in SAS (version 9.2, SAS Institute Inc.). The model specified day as a repeated measure and tested day and day $\times$ treatment interaction. Residuals from the model were plotted against the predicted values to verify assumptions of normality and homogeneity of variance. Data were analyzed separately in 3 periods: preweaning (d 1 to d 35), weaning (d 36 to d 40), and postweaning (d 41 to d 55).

\section{RESULTS}

\section{Milk Intake and Visits to the Milk Feeder}

Milk intakes were similar for groups housed with an older weaned companion and groups housed with calves of similar age. During the preweaning period, the duration and total number of visits to the milk feeder did not differ between treatments. During the weaning period, the total number of visits and the number of unrewarded visits to the milk feeder was lower for calves housed with an older weaned companion (Figure 1). During the postweaning period, the average time spent at the milk feeder decreased but did not differ with treatment (Table 1).

\section{Starter Intake and Visits to the Starter Feeder}

During the preweaning period, calves housed with an older companion visited the starter feeder more often and spent more time at the feeder than did calves housed in groups of similar age. Starter intake did not differ between treatments and increased with calf age $(P=0.0001)$ from (mean $\pm \mathrm{SD}) 24.2 \pm 15.9 \mathrm{~g} / \mathrm{d}$ during the first 2 wk to (mean \pm SD) $197.2 \pm 87.9 \mathrm{~g} / \mathrm{d}$ during the rest of the preweaning period (Figure 2). During the weaning period, starter intake did not differ between treatments but calves housed with an older companion spent more time at the starter feeder than did calves housed in groups of similar age. During the postweaning period, calves housed with an older companion also spent more time at the starter feeder and consumed more starter compared with calves housed in groups of similar age (Table 2).

\section{Hay Intake and Visits to the Hay Feeder}

Hay intake during the preweaning period was higher for calves housed with an older weaned social companion (Figure 3); these calves also spent more time at the hay feeder and visited the feeder more often during this period. During the weaning period, hay intake, the number of visits, and time spent at the hay feeder were similar for the 2 treatments. During the postweaning period, hay intake and the number of visits to the hay feeder did not differ between the 2 treatments, but calves housed with an older companion spent less

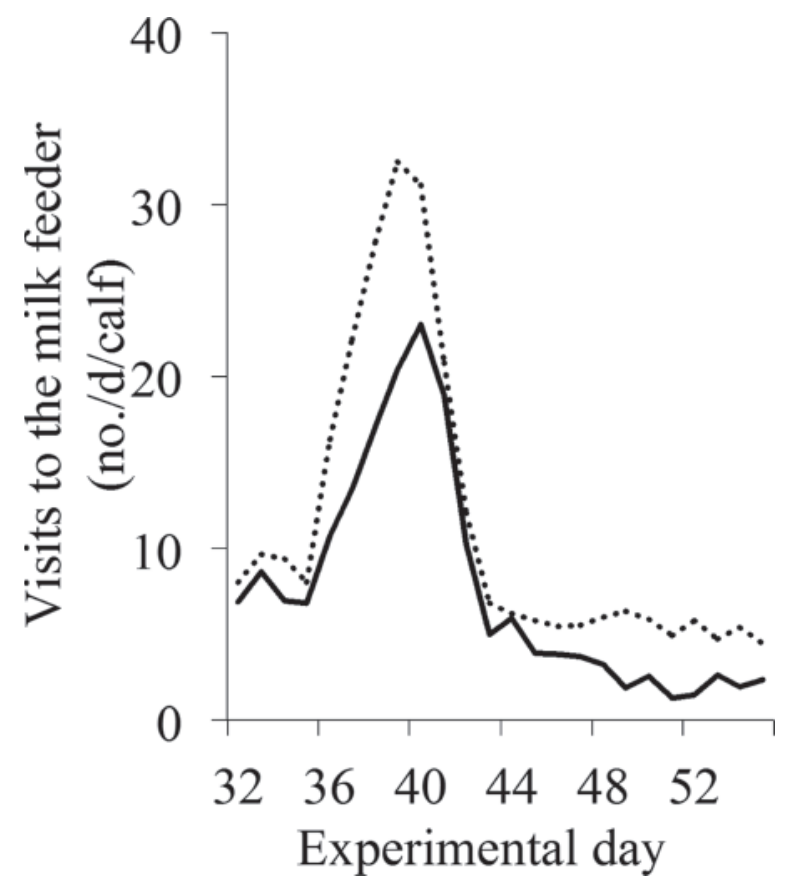

Figure 1. Mean number of visits to the milk feeder (no./d) for calves housed with an older weaned companion (solid line; $\mathrm{n}=9$ pens, 2 young calves/pen) and for calves of similar age (dotted line; $\mathrm{n}=9$ pens, 3 young calves/pen) during the weaning (d 36 to 40) and postweaning periods (d 41 to 55 ). 
Table 1. Mean intake of milk $(\mathrm{kg} / \mathrm{d})$, number of unrewarded visits (no./d), and number (no./d) and duration $(\mathrm{min} / \mathrm{d})$ of visits to the milk feeder for calves housed with an older weaned companion ( $\mathrm{n}=9$ pens; 2 young calves/pen) and for calves of similar age ( $\mathrm{n}=9$ pens; 3 young calves/pen)

\begin{tabular}{lcrll}
\hline Item & $\begin{array}{c}\text { Calves with an } \\
\text { older companion }\end{array}$ & $\begin{array}{c}\text { Calves of } \\
\text { similar age }\end{array}$ & SE & $P$-value \\
\hline Preweaning period (d 1 to 35) & & & & \\
Milk intake (kg/d) & 7.6 & 7.6 & 0.1 & 0.64 \\
Unrewarded visits to the feeder (no./d) & 8.8 & 9.2 & 0.5 & 0.6 \\
Total visits to the feeder (no./d) & 14.3 & 14.8 & 0.6 & 0.53 \\
Duration (min/d) & 69.3 & 69.8 & 3.0 & 0.88 \\
Weaning period (d 36 to 40) & 3.8 & 3.8 & 0.1 & 0.8 \\
Milk intake (kg/d) & 17.0 & 26.1 & 1.9 & 0.0043 \\
Unrewarded visits to the feeder (no./d) & 20.3 & 29.6 & 2.0 & 0.0045 \\
Total visits to the feeder (no./d) & 123.2 & 152.5 & 22.2 & 0.37 \\
Duration (min/d) (d 41 to 55) & 4.7 & 7.0 & 1.3 & 0.22 \\
Postweaning period (no./d) & & & & \\
Unrewarded visits to the feeder (no./d) & 1.0 & 1.0 & 0.1 & 0.91 \\
Duration (min/d) & & & & \\
\hline
\end{tabular}

time at the hay feeder compared with calves housed in groups of similar age (Table 3$)$.

\section{Growth Rate}

Calves housed with an older weaned companion gained more weight during the preweaning (0.89 vs. $0.76 \pm 0.03 \mathrm{~kg} / \mathrm{d} ; P=0.01)$ and postweaning (1.4 vs. $1.1 \pm 0.05 \mathrm{~kg} / \mathrm{d} ; P=0.009)$ periods compared with

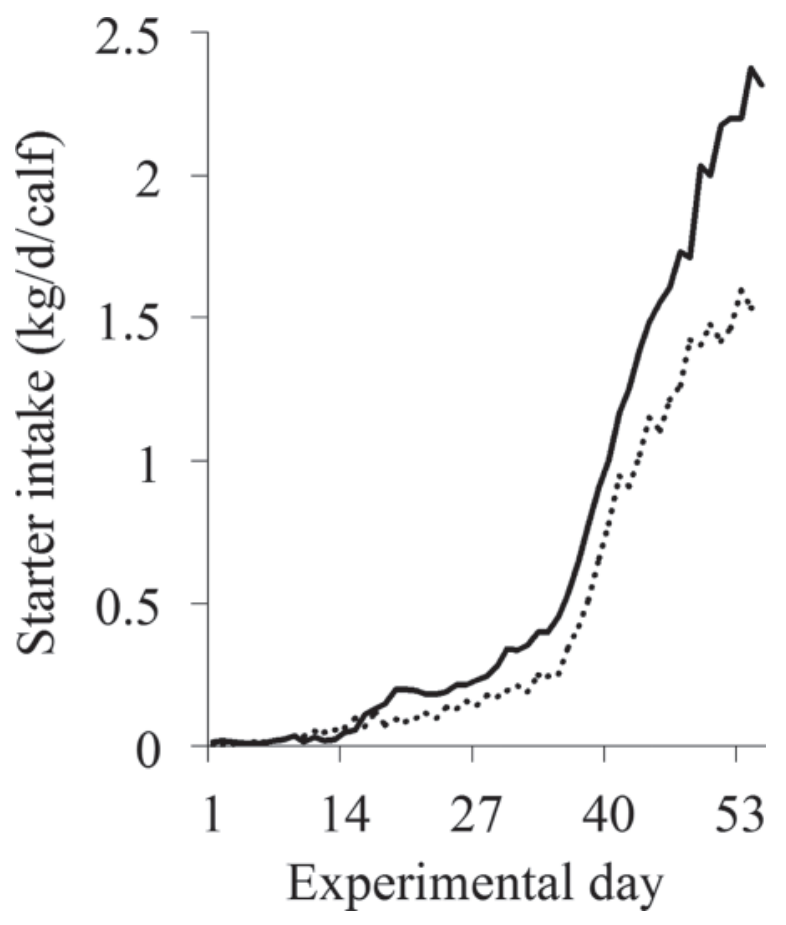

Figure 2. Mean intake of starter $(\mathrm{kg} / \mathrm{d})$ for calves housed with an older weaned companion (solid line; $\mathrm{n}=9$ pens, 2 young calves/pen) and for calves of similar age (dotted line; $\mathrm{n}=9$ pens, 3 young calves/ pen) during the preweaning (d 1 to 35 ), weaning (d 36 to 40), and postweaning (d 41 to 55 ) periods. calves housed with same-age calves. During the weaning period, weight gain did not differ among treatments $(0.45$ vs. $0.37 \pm 0.16 \mathrm{~kg} / \mathrm{d} ; P=0.7)$.

\section{DISCUSSION}

During the preweaning period, calves housed with an older weaned companion visited the hay and starter feeders more often and spent more time at the feeders than did calves housed in a uniform age group. As calves in both treatments consumed similar amounts of milk and starter preweaning, the higher intake of hay by calves housed with an older weaned companion may have contributed to their slightly higher weight gains preweaning. It has long been believed that feeding calves hay early in life compromises starter intake and calf growth (Warner et al., 1956; Stobo et al., 1966), but recent work suggests that the opposite may be true, at least for calves fed higher quantities of milk. For these calves, hay intake does not decrease weight gain or rumen development, but enhances rumen weight and physical capacity and increases rumination (Khan et al., 2011). Moreover, the presence of an older companion could have also increased the availability of microorganisms in the environment, allowing earlier inoculation of fauna and flora in the digestive tract of the young calves housed with an older companion (Pounden and Hibbs, 1948). The consequences of this early inoculation on feed digestibility and calf growth are not well understood. We encourage more work on how early rumen inoculation (flora and fauna) may interact and trigger rumen development, especially for calves fed high milk volumes and provided forages during the preweaning period.

This increased affinity for solid feed early in life by calves provided the company of an older weaned companion could be the result of social learning (Galef, 
Table 2. Mean intake of starter (g/d) and number (no./d) and duration (min/d) of visits to the starter feeder for calves housed with an older weaned companion ( $\mathrm{n}=9$ pens; 2 young calves/pen) and for calves of similar age $(\mathrm{n}=9$ pens; 3 young calves/pen)

\begin{tabular}{lcrrl}
\hline & $\begin{array}{c}\text { Calves with an } \\
\text { older companion }\end{array}$ & $\begin{array}{c}\text { Calves of } \\
\text { similar age }\end{array}$ & SE & $P$-value \\
\hline Preweaning period (d 1 to 35) & & & & \\
$\quad$ Starter intake (g/d) & 156.2 & 99.8 & 30.5 & 0.21 \\
Total visits to the feeder (no./d) & 15.2 & 9.4 & 0.6 & 0.0001 \\
$\quad$ Total duration at the feeder (min/d) & 6.5 & 3.4 & 0.5 & 0.001 \\
Weaning period (d 36 to 40) & 765.3 & 541.9 & 96.7 & 0.12 \\
$\quad$ Starter intake (g/d) & 24.9 & 20.7 & 1.9 & 0.15 \\
Total visits to the feeder (no./d) & 22.1 & 12.9 & 1.9 & 0.003 \\
Total duration at the feeder (min/d) & & & & \\
Postweaning period (d 41 to 55) & $1,794.5$ & $1,296.6$ & 86.3 & 0.001 \\
Starter intake (g/d) & 29.0 & 25.8 & 1.3 & 0.08 \\
Total visits to the feeder (no./d) & 41.4 & 28.2 & 3.7 & 0.03 \\
Total duration at the feeder (min/d) & & & & \\
\hline
\end{tabular}

1993; Galef and Giraldeau, 2001). For example, local enhancement (a nonimitative process defined as attraction of observers to a location at which conspecifics are behaving; Thorpe, 1956) may explain the increased exploratory behavior (e.g., higher number and duration of visits to the starter and hay feeders) observed in calves provided the company of an older weaned companion. Olfactory stimulation, independent of

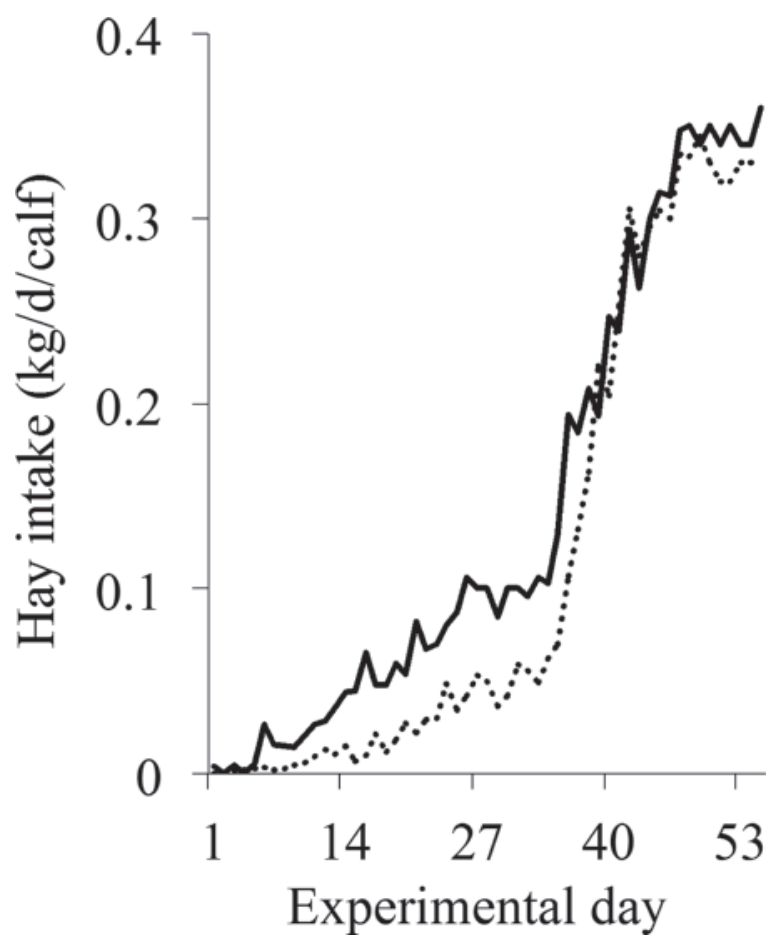

Figure 3. Mean intake of hay $(\mathrm{kg} / \mathrm{d})$ for calves housed with an older weaned companion (solid line; $\mathrm{n}=9$ pens, 2 young calves/pen) and for calves of similar age (dotted line; $\mathrm{n}=9$ pens, 3 young calves/ pen) during the preweaning ( 1 to 35 ), weaning (d 36 to 40), and postweaning (d 41 to 55$)$ periods. imitation, may also explain our results. For example, in rats, some information about feed is transferred between individuals via the feed odors in the breath of the demonstrator animal (Galef, 1994); young calves may have also been influenced by the odors of hay and starter on the breath of the older companion, triggering them to experiment with feeds of similar smell. Young calves may have also imitated the behavior of the older weaned companion, but this explanation requires some understanding by the young calf of the goals (e.g., at weaning it is necessary to ingest alternative feeds) or consequences (e.g., to avoid hunger) of the behavior being observed (Tomasello, 1990). The current study was not designed to distinguish among these different types of social learning but we encourage future work to understand the mechanisms at play.

Throughout their development, dairy calves are exposed to a range of management practices (e.g., introduction to new feeding systems, regrouping, social isolation, abrupt weaning, and other changes in diet) that require considerable behavioral flexibility to adapt. Work on behavioral plasticity that allows calves to adapt to stressful events is only just beginning (De Paula Vieira et al., 2010), and the extent to which lack of behavioral plasticity can result in the maladjustment of dairy calves to commercial systems is not well documented. Social learning is more likely to occur when prior experience is not enough to decrease uncertainty in unpredictable situations that require behavioral flexibility (Dewar, 2004; Kendal et al., 2004; Galef et al., 2008); future studies that assess the mechanisms and potential benefits of social learning in dairy calves are now required.

In our experiment, calves were expected to go from a milk-based diet to one based only on solid feed over a 5 -d period starting at about 5 wk of age. Calves provided an older weaned companion seemed to adopt more suc- 
Table 3. Mean intake of hay $(\mathrm{g} / \mathrm{d})$ and number (no./d) and duration (min/d) of visits to the hay feeder for calves housed with an older weaned companion ( $\mathrm{n}=9$ pens; 2 young calves/pen) and for calves of similar age ( $\mathrm{n}=9$ pens; 3 young calves/pen)

\begin{tabular}{lcccc}
\hline Item & $\begin{array}{c}\text { Calves with an } \\
\text { older companion }\end{array}$ & $\begin{array}{c}\text { Calves of } \\
\text { similar age }\end{array}$ & SE & $P$-value \\
\hline Preweaning period (d 1 to 35) & & & & \\
$\quad$ Hay intake (g/d) feer (no./d) & 57.9 & 25.6 & 4.7 & 0.0002 \\
Total visits to the feeder & 8.8 & 5.1 & 0.5 & 0.0001 \\
$\quad$ Total duration at the feeder (min/d) & 13.2 & 8.2 & 1.1 & 0.004 \\
Weaning period (d 36 to 40) & 205.3 & 161.3 & 31.1 & 0.33 \\
Hay intake (g/d) & 21.3 & 16.5 & 3.9 & 0.39 \\
Total visits to the feeder (no./d) & 32.8 & 38.6 & 4.5 & 0.37 \\
Total duration at the feeder (min/d) & & & & \\
Postweaning period (d 41 to 55) & 292.1 & 306.6 & 27.0 & 0.70 \\
Hay intake (g/d) & 25.0 & 28.6 & 2.7 & 0.35 \\
Total visits to the feeder (no./d) & 32.5 & 58.5 & 5.5 & 0.005 \\
Total duration at the feeder (min/d) & & & & \\
\hline
\end{tabular}

cessful feeding strategies that allowed improved weight gains after weaning. For example, during the postweaning period, calves housed with an older companion spent more time at the starter feeder. Consequently, they consumed more starter and gained more weight. In contrast, calves housed with companions of similar age visited the milk feeder more often during the weaning period. Because the visits to the milk feeder were mostly unrewarded during this period, performing this behavior provided no real benefits to the calves. Calves fed less milk (i.e., $4 \mathrm{~L} / \mathrm{d}$ vs. $8 \mathrm{~L} / \mathrm{d}$ ) also visit the milk feeder more frequently, even when these visits result in no extra milk (De Paula Vieira et al., 2008), indicating that these visits are associated with hunger.

The higher postweaning weight gains of calves provided an older weaned companion may be a consequence of higher hay intakes during the preweaning period. These higher intakes may have allowed calves to develop a better functioning rumen (e.g., by increasing rumen capacity and rumination; Hibbs et al., 1956; Tamate et al., 1962; van Ackeren et al., 2009), so that after weaning calves housed with an older companion were better able to utilize the starter. It is known that solid feed intake abruptly increases when milk is no longer provided (Khan et al., 2011). The effects of this higher intake of starter on calf rumen metabolism and morphology is not well described in the literature, but we speculate that calves provided the company of an older companion may have been less affected by the negative effects of low rumen $\mathrm{pH}$, such as rumenitis and papillae branching (Nocek et al., 1984; Suárez et al., 2006a,b). We encourage future studies on the early ruminal development of young dairy calves fed higher milk volumes that test specific properties of solid diets (e.g., palatability, digestibility, rumen growth, and capacity) that are relevant at triggering early rumen development preweaning and minimize rumen overload postweaning.

\section{CONCLUSIONS}

This is the first study to report the benefits of social learning on the behavior and performance of dairy calves before and after weaning from milk. Providing young calves an older weaned companion increased solid feed intake and improved growth rate before and after weaning from milk. Future work needs to determine the social learning mechanisms at play that result in these benefits.

\section{ACKNOWLEDGMENTS}

Andreia De Paula Vieira was sponsored by the CAPES Foundation of the Ministry of Education of Brazil. We thank the students and staff at UBC's Dairy Education and Research Centre who helped in this experiment, especially Carolina L. H. Abrahao, Juliana S. Oliveira, Laura B. Lins, and Pierre Groenenboom. This project was funded by a Discovery grant to DMW from Canada's Natural Sciences and Engineering Research Council (NSERC, Ottawa, ON, Canada). General funding for UBC's Animal Welfare Program is by NSERC's Industrial Research Chair Program with industry contributions from the Dairy Farmers of Canada (Ottawa, ON, Canada), Westgen Endowment Fund (Milner, BC, Canada), Pfizer Animal Health (Kirkland, QC, Canada), BC Cattle Industry Development Fund (Kamloops, BC, Canada), the BC Milk Producers (Burnaby, BC, Canada), BC Dairy Foundation (Burnaby, BC, Canada), BC Dairy Education and Research Association (Abbotsford, BC, Canada), and Alberta Milk (Edmonton, AB, Canada). 


\section{REFERENCES}

de Passillé, A. M., F. T. Borderas, and J. Rushen. 2011. Weaning age of calves fed a high milk allowance by automated feeders: Effects on feed, water, and energy intake, behavioral signs of hunger, and weight gains. J. Dairy Sci. 94:1401-1408.

De Paula Vieira, A., V. Guesdon, A. M. de Passillé, M. A. G. von Keyserlingk, and D. M. Weary. 2008. Behavioral indicators of hunger in dairy calves. Appl. Anim. Behav. Sci. 109:180-189.

De Paula Vieira, A., M. A. G. von Keyserlingk, and D. M. Weary. 2010. Effects of pair versus single housing on performance and behavior of dairy calves before and after weaning from milk. J. Dairy Sci. 93:3079-3085.

Dewar, G. 2004. Social and asocial cues about new food: Cue reliability influences intake in rats. Learn. Behav. 32:82-89.

Fukusawa, M., S. Sato, and K. Sugawara. 1999. Influence of early social learning on later feeding behavior of novel food in calves. Anim. Sci. J. 70:356-359.

Galef, B. G., Jr. 1977. Social transmission of food preferences: An adaptation for weaning in rats. J. Comp. Physiol. Psychol. 91:11361140.

Galef, B. G., Jr. 1993. Functions of social learning about food: A causal analysis of effects of diet novelty on preference transmission. Anim. Behav. 46:257-265.

Galef, B. G., Jr. 1994. Olfactory communications about foods among rats: A review of recent findings. Pages 83-101 in Behavioral Aspects of Feeding. B. G. Galef, M. Mainardi, and P. Valsecchi, ed. Harwood Academic Publishers GmbH, Chur, Switzerland.

Galef, B. G., Jr., K. E. Dudley, and E. E. Whiskin. 2008. Social learning of food preferences in 'dissatisfied' and 'uncertain' Norway rats. Anim. Behav. 75:631-637.

Galef, B. G., and L. A. Giraldeau. 2001. Social influences on foraging in vertebrates: Causal mechanisms and adaptive functions. Anim. Behav. 61:3-15

Galef, B. G., Jr., and M. Stein. 1985. Demonstrator influence on observer diet preference: Analyses of critical social interactions and olfactory signals. Anim. Learn. Behav. 13:31-38.

Hafez, E. S. E., and J. A. Lineweaver. 1968. Suckling behavior in natural and artificially fed neonate calves. Z. Tierpsychol. 25:187-198.

Hibbs, J. W., H. R. Conrad, W. D. Pounden, and N. Frank. 1956. A high roughage system for raising calves based on early development of rumen function. VI. Influence of hay to grain ratio on calf performance, rumen development, and certain blood changes. J Dairy Sci. 39:171-179.

Kendal, R. L., I. Coolen, and K. N. Laland. 2004. The role of conformity in foraging when personal and social information conflict. Behav. Ecol. 5:269-277.

Key, C., and R. M. MacIver. 1980. The effects of maternal influences on lambs: Breed differences in grazing, resting and courtship behavior. Appl. Anim. Ethol. 6:33-48.

Khan, M. A., D. M. Weary, and M. A. G. von Keyserlingk. 2011. Hay intake improves performance and rumen development of calves fed higher quantities of milk. J. Dairy Sci. 94:3547-3553.

Lynch, J. J., R. G. Keogh, R. L. Elwin, G. C. Green, and B. E. Mottershead. 1983. Effects of early experience on the postweaning ac- ceptance of whole grain wheat by fine-wool merino lambs. Anim. Prod. 36:175-183.

Mirza, S. N., and F. D. Provenza. 1994. Socially induced food avoidance in lambs: Direct or indirect maternal influence? J. Anim. Sci. 72:899-902

Nocek, J. E., C. W. Heald, and C. E. Polan. 1984. Influence of ration physical form and nitrogen availability on ruminal morphology of growing bull calves. J. Dairy Sci. 67:334-343.

Nolte, D. L., F. D. Provenza, and D. F. Balph. 1990. The establishment and persistence of food preferences in lambs exposed to selected foods. J. Anim. Sci. 68:998-1002.

Pounden, W. D., and J. W. Hibbs. 1948. The influence of the ration and rumen inoculation on the establishment of certain microorganisms in the rumens of young calves. J. Dairy Sci. 31:1041-1050.

Reinhardt, V., and A. Reinhardt. 1981. Natural suckling performance and age of weaning in zebu cattle (Bos indicus). J. Agric. Sci. 96:309-312.

Stobo, I. J. F., J. H. B. Roy, and H. J. Gaston. 1966. Rumen development in the calf. 1 . The effect of diets containing different proportions of concentrates to hay on rumen development. Br. J. Nutr. $20: 171-188$.

Suárez, B. J., C. G. Van Reenen, G. Beldman, J. van Delen, J. Dijkstra, and W. J. J. Gerrits. 2006a. Effects of supplementing concentrates differing in carbohydrate composition in veal calf diets: I. Animal performance and rumen fermentation characteristics. J. Dairy Sci. 89:4365-4375.

Suárez, B. J., C. G. Van Reenen, W. J. J. Gerrits, N. Stockhofe, A. M van Vuuren, and J. Dijkstra. 2006b. Effects of supplementing concentrates differing in carbohydrate composition in veal calf diets: II. Rumen development. J. Dairy Sci. 89:4376-4386.

Tamate, H., A. D. McGilliard, N. L. Jacobson, and R. Getty. 1962 Effect of various dietaries on the anatomical development of the stomach in the calf. J. Dairy Sci. 45:408-420.

Thorpe, W. 1956. Learning and Instinct in Animals. Methuen, London, UK.

Tomasello, M. 1990. Cultural transmission in the tool use and communicatory signaling of chimpanzees? Pages 274-311 in Language and Intelligence in Monkeys and Apes: Comparative Developmental Perspectives. S. Parker and K. Gibson, ed. Cambridge University Press, Cambridge, UK.

van Ackeren, C., H. Steingaß, K. Hartung, R. Funk, and W. Drochner. 2009. Effect of roughage level in a total mixed ration on feed intake, ruminal fermentation patterns and chewing activity of early weaned calves with ad libitum access to grass hay. Anim. Feed Sci. Technol. 153:48-59.

Vickers, K. J., L. Niel, L. M. Kiehlbauch, and D. M. Weary. 2005. Calf response to caustic paste and hot-iron dehorning using sedation with and without local anesthetic. J. Dairy Sci. 88:1454-1459.

Vitale, A. F., M. Tenucci, M. Papini, and S. Lovari. 1986. Social behavior of the calves of semi-wild Maremma cattle, Bos primigenius taurus. Appl. Anim. Behav. Sci. 16:217-231.

Warner, R. G., W. P. Flatt, and J. K. Loosli. 1956. Dietary factors influencing the development of the animal's stomach. J. Agric. Food Chem. 4:788-792. 